Pacific Journal of Mathematic 


\title{
MEAN VALUES OF HARMONIC FUNCTIONS ON HOMOTHETIC CURVES
}

\author{
JOHN W. GREen
}

1. Introduction. It is well known indeed that if $U(P)$ is harmonic in the plane the mean value of $U$ taken over the perimeter or the area of a circle with center $P_{0}$ equals $U\left(P_{0}\right)$. A related result is that of Ásgeirsson [1] which states that mean of $U$ over the area of any one of a family of confocal ellipses equals that over any other. The same is true for the means over the perimeters, provided the means are weighted by integrating with respect to the anomaly angle instead of arc length.

It would be interesting to know if there are any other simple families of curves over which the perimeter or area average is constant. The simplest families to try are homothetic families, and in the following we show that under suitable regularity assumptions, there are none of these except circles.

2. Perimeter means. Let $C$ be a closed simple rectifiable curve containing $O$ in its interior. We suppose that $C$ is smooth enough that its Green's function $g(P)$ with pole at $O$ is continuously differentiable on $C$, as will be the case if $C$ has a continously turning tangent line. By $C_{\lambda}$ we mean the curve obtained from $C$ through the homothetic transformation $x^{\prime}=\lambda x, y^{\prime}=\lambda y$. If we expect that for $\lambda<1, C_{\lambda}$ is inside $C$, we should assume that $C$ is star-shaped about $O$, although this is not essential to what follows. A positive continuous weight function $w(P)$ is given, and we suppose that the mean of $U$ with weight $w$ over all $C_{\lambda}$ is constant, provided $U$ is harmonic inside and on $C$.

We immediately note two things. In the first place, letting $\lambda$ tend to zero, we see that the mean value of $U$ over $C_{\lambda}$ must be $U(O)$. In the second place, from obvious continuity considerations, we see that $U$ need only be harmonic inside $C$ and continuous on $C$ for the mean over $C_{\lambda}$ to be constant. Since $U$ may be given arbitrary continuous values on $C$ and determined inside so as to be harmonic, it follows that

$$
U(O)=\frac{1}{W} \int_{O} U(P) w(P) d s
$$

for every continuous $U$, where $W=\int_{\sigma} w(P) d s$. But also 


$$
U(O)=\frac{1}{2 \pi} \int_{\sigma} U(P) \frac{\partial g}{\partial n}(P) d s,
$$

and so $\int_{0} U\{\partial g / \partial n-(2 \pi / W) w\} d s=0$ for continuous $U$.

Thus

$$
\frac{\partial g}{\partial n}=\frac{2 \pi w}{W}
$$

that is, the weight function must be the obvious one, $\partial g / \partial n$. In the case of the ordinary perimeter mean, $w=1$ and $\partial g / \partial n=$ constant. This implies that $C$ is a circle. For consider $f(z)=e^{-(g+i h)}$ which maps the interior of $C$ into the unit circle. On $C, f^{\prime}(z)$ remains continuous and $|f(z)|=\partial h / \partial s=\partial g / \partial n=$ constant. Thus $f^{\prime}=$ constant and $f(z)=$ constant $z$ and the result is obvious.

3. Area means. Let the equation in polar coordinates of $C$ be $r=f(\theta)$. Saying that the mean of $U$ over the interior of $C_{\lambda}$ is constant for all $\lambda \leqq 1$ amounts to saying that

$$
U(O)=\frac{\int_{0}^{2 \pi} d \theta \int_{0}^{\lambda f(\theta)} U(r, \theta) r d r}{\int_{0}^{2 \pi} \int_{0}^{\lambda f(\theta)} r d r}
$$

If the derivative of the right hand member with respect to $\lambda$ is computed for $\lambda=1$ and equated to zero, there results

$$
U(O)=k \int_{0}^{2 \pi} U(f(\theta), \theta) f^{2}(\theta) d \theta=k \int_{C} U f \cos \psi d s,
$$

where $\psi$ is the angle between radius vector and normal to $C$ and $k$ is a constant. Thus the problem is reduced to one involving a perimeter mean, and as in $\S 2$ we see that

$$
2 \pi k f \cos \psi=\partial g / \partial n
$$

This equation says, among other things, that $\partial g / \partial n$ has a lesser value at the nearest than at the farthest points of $C$ from $O$. In the next section we show that this can be true only if $C$ is a circle about $O$.

4. A lemma. Let $P$ and $Q$ be a nearest and farthest point, respectively, of $C$ from 0 . To complete our discussion of the area means we shall show that $(\partial g / \partial n)_{Q} \leqq 1 / O Q<1 / O P \leqq(\partial g / \partial n)_{P}$, which will certainly contradict the result obtained in the previous section unless 
$O P=O Q$ and $C$ is a circle. To this end we prove ${ }^{1}$ the following lemma, which can be interpreted as a special case of Julia's theorem [2]. The present proof is included because it avoids the use of conformal mapping, and also because its proof is somewhat shorter than the steps required to derive the lemma from the usual statements of Julia's theorem.

Lemma. Let $D_{1}$ and $D_{2}$ be domains with smooth boundaries, with $O \in D_{1} \subset D_{2}$. Let the corresponding Green's functions be $g_{1}$ and $g_{2}$. If $P$ is on both boundaries, then $\partial g_{2} / \partial n \geq \partial g_{1} / \partial n$.

Let the boundaries be $C_{1}$ and $C_{2}$, and set $h=g_{2}-g_{1}$. Then $h$ is harmonic in $D_{1}$, and on the boundary $C_{1}, h=g_{2} \geqq 0$. Thus $h \geqq 0$ in $D_{1}$. Since $h=0$ at $P$, clearly $0 \leqq \partial h / \partial n=\partial g_{2} \cdot \partial n-\partial g_{1} \partial n$, and the lemma follows.

Returning to the matter discussed at the beginning of this section, we see that by comparing $C$ first with its largest inscribed circle with center at $O$, and then with the smallest circumscribed circle, the stated inequalities follow immediately.

5. Concluding remarks. These results have considerable room for improvement in the direction of lightening the restriction on $C$. One would suppose that in the perimeter case, $\mathrm{C}$ should only be required to be rectifiable, and in the area case, no condition at all on $C$ need be put.

The lemma provides an alternate way, avoiding conformal mapping, of completing the discussion of the perimeter means. With this in mind, it would be quite easy to extend the whole discussion to harmonic functions in more than two dimensions.

It is interesting to note another and quite different form in which the area problem can be cast. If the area means of any harmonic function over the homothetic transforms of $r \leqq f(\theta)$ are to be constant, this must be true for the simplest ones, $U=r^{n} e^{ \pm i n \theta}$. This leads immediately to the equations

$$
\int_{0}^{2 \pi} f^{n+2}(\theta) \cos n \theta d \theta=\int_{0}^{2 \pi} f^{n+2}(\theta) \sin n \theta d \theta=0
$$

for $n=1,2, \ldots$ Our results show indirectly that if $f$ is positive and sufficiently smooth, the above orthogonality conditions imply that $f=$ constant. It would be interesting to obtain a direct proof of this without the intervention of potential theory.

1 The proof given, which is somewhat simpler than that originally devised by the author, is due to Professor David Gilbarg. 


\section{REFERENCES}

1. L. Ásgeirsson, Über eine Mittelwertseigenschaft von Lösungen homogener linearer partieller Differentialgleichungen 2. Ordnung mit konstanten Koeffizienten, Math. Ann. 113 (1937), 321-346.

2. L. Bieberbach, Lehrbuch der Funktionentheorie, Vol. II, pp. 112-114. Teubner., Leipzig, 1921.

UNIVERSity OF CALIFORNiA, LOS ANGELES 


\section{PACIFIC JOURNAL OF MATHEMATICS}

EDITORS

\author{
H. L. Royden \\ Stanford University \\ Stanford, California \\ E. Hewite \\ University of Washington \\ Seattle 5 , Washington
}

\author{
R. P. Dilworth \\ California Institute of Technology \\ Pasadena 4, California
}

\author{
A. Horn* \\ University of California \\ Los Angeles 24, California
}

\section{ASSOCIATE EDITORS}
E. F. BECKENBACH
M. HALL
M. S. KNEBELMAN
J. J. STOKER
C. E. BURGESS
P. R. HALMOS
I. NIVEN
V. GANAPATHY IYER
T. G. OSTROM
G. SZEKERES
H. BUSEMANN
R. D. JAMES
M. M. SCHIFFER
F. WOLF
H. FEDERER

\section{SPONSORS}

\author{
UNIVERSITY OF BRITISH COLUMBIA \\ CALIFORNIA INSTITUTE OF TECHNOLOGY \\ UNIVERSITY OF CALIFORNIA \\ CALIFORNIA RESEARCH CORPORATION \\ MONTANA STATE UNIVERSITY \\ UNIVERSITY OF NEVADA \\ OREGON STATE COLLEGE \\ UNIVERSITY OF OREGON \\ UNIVERSITY OF SOUTHERN CALIFORNIA
}

\author{
STANFORD UNIVERSITY \\ UNIVERSITY OF UTAH \\ WASHINGTON STATE COLLEGE \\ UNIVERSITY OF WASHINGTON \\ AMERICAN MATHEMATICAL SOCIETY \\ HUGHES AIRCRAFT COMPANY
}

Mathematical papers intended for publication in the Pacific Journal of Mathematics should be typewritten (double spaced), and the author should keep a complete copy. Manuscripts may be sent to any of the editors. Manuscripts intended for the outgoing editors should be sent to their successors. All other communications to the editors should be addressed to the managing editor, Alfred Horn at the University of California, Los Angeles 24, California.

50 reprints of each article are furnished free of charge; additional copies may be obtained at cost in multiples of 50 .

The Pacific Journal of Mathematics is published quarterly, in March, June, September, and December. The price per volume (4 numbers) is $\$ 12.00$; single issues, $\$ 3.50$. Back numbers are available. Special price to individual faculty members of supporting institutions and to individual members of the American Mathematical Society: $\$ 4.00$ per volume; single issues, $\$ 1.25$.

Subscriptions, orders for back numbers, and changes of address should be sent to Pacific Journal of Mathematics, c/o University of California Press, Berkeley 4, California.

Printed at Kokusai Bunken Insatsusha (International Academic Printing Co., Ltd.), No. 10, 1-chome, Fujimi-cho, Chiyoda-ku, Tokyo, Japan.

* During the absence of E. G. Straus.

PUBLISHED BY PACIFIC JOURNAL OF MATHEMATICS, A NON-PROFIT CORPORATION COPYRIGHT 1956 BY PACIFIC JOURNAL OF MATHEMATICS 


\section{Pacific Journal of Mathematics}

\section{Vol. 6, No. $2 \quad$ December, 1956}

Louis Auslander, Remark on the use of forms in variational calculations .......................................... 209

Hubert Spence Butts, Jr. and Henry B. Mann, Corresponding residue systems in algebraic number fields ........................ 211

L. Carlitz and John Herbert Hodges, Distribution of matrices in a finite field............................................

Paul Civin and Bertram Yood, Invariant functionals ............... 231

David James Dickinson, Henry Pollak and G. H. Wannier, On a class of polynomials orthogonal over a denumerable set .................

Bernard Friedman and Luna Mishoe, Eigenfunction expansions associated with a non-self-adjoint differential equation ....................

Luna Mishoe and G. C. Ford, On the uniform convergence of a certain eigenfunction series .............................. 271

John W. Green, Mean values of harmonic functions on homothetic curves...........................................

Charles John August Halberg, Jr. and Angus E. Taylor, On the spectra of linked operators .....................................

Chuan Chih Hsiung, Some integral formulas for closed hypersurfaces in Riemannian space ................................... 291

Norman D. Lane, Differentiable points of arcs in conformal n-space 301

Louis F. McAuley, A relation between perfect separability, completeness, and normality in semi-metric spaces

G. Power and D. L. Scott-Hutton, The slow shearing motion of a liquid past a semi-infinite plane .............................

A. C. Schaeffer, Entire functions

Edward Silverman, An intrinsic inequality for Lebesgue area...

Choy-Tak Taam, Asymptotic relations between systems of differential equations.

Ti Yen, Quotient algebra of a finite $A W^{*}$-algebra ... 